DOE/PC/89760-Tll

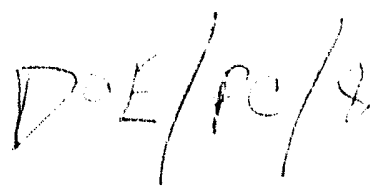

DE93 0012.69

\title{
A NOVEL APPROACH TO HIGHLY DISPERSING CATALYTIC MATERIALS IN COAL FOR GASIFICATION
}

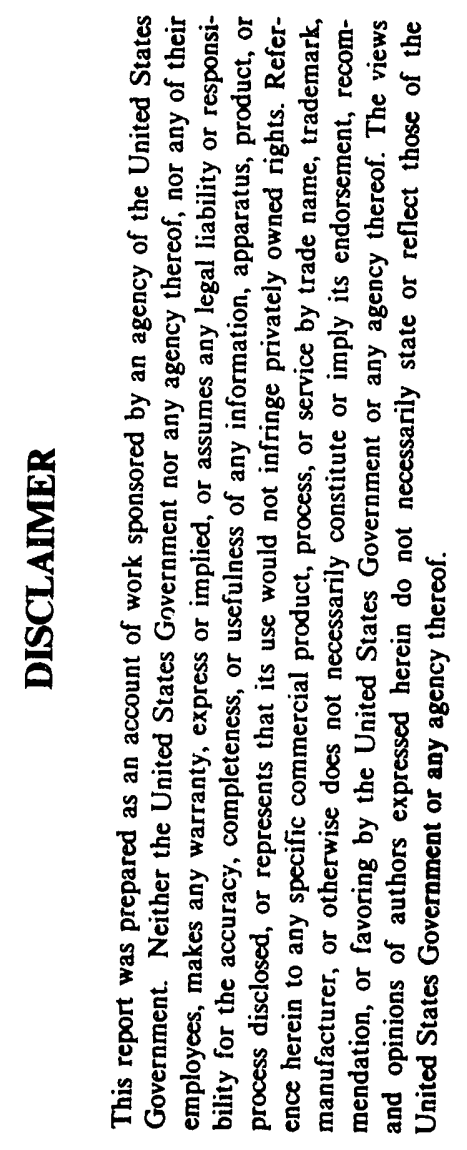

\author{
Fleventh Quarterly Report \\ for the Period \\ April 1, 1992 - June 30, 1992 \\ Godfried M.K. Abotsi and Kofi B. Bota \\ Principal Investigators \\ Research Center for Science and Technology \\ Clark Atlanta University \\ Atlanta, GA 30314 \\ PREPARED FOR \\ UNITED STATES DEPARTMENT OF ENERGY \\ UNDER CONTRACT NO.L DE FG22-89PC89760
}

\section{MASTER}




\begin{abstract}
This project seeks to develop a technique, based on coal surface properties, for highly dispersing catalysts in coal for gasification and to investigate the potential of using potassium carbonate and calcium acetate mixtures as catalysts for coal gasification. The lower cost and higher catalytic activity of the latter compound will produce economic benefits by reducing the amount of $\mathrm{K}_{2} \mathrm{CO}_{3}$ required for high coal char reactivities.

As was shown in previous reports, coal loading with potassium or calcium at different $\mathrm{pHs}$ produced $\mathrm{CO}_{2}$ gasification activities which increased in the order $\mathrm{pH}$ $6>\mathrm{pH} 10>>\mathrm{pH}$ 1. A similar trend was obtained when calcium and potassium were simultaneously loaded and char reaction times were less than about $75 \mathrm{~min}$. In the last quarter, the potential application of ammonia as a reactive medium for coal gasification has been investigated. This gas has not been previously applied to coal gasification. However, related work suggests that the potential chemical feedstock base can be broadened by using ammonia to generate hydrogen cyanide and cyanogen from coal. The current report shows that the reactivity of a demineralized lignite in ammonia is significantly higher in the presence of calcium or potassium catalyst than that for the char without added catalyst and suggests that ammonia is a potentially reactive gas for catalyzed coal gasification.
\end{abstract}




\section{INTRODUCTION}

Previous studies have shown that ammonia [1-14] and amines $[11,12,15,16]$ react with carbon at elevated temperatures (above $\sim 300^{\circ} \mathrm{C}$ ). In general, the goal of these studies is to introduce nitrogen functionality to the carbon surface. The level of nitrogen incorporation varies with reaction temperature and the type of carbon. The ammonia or amine-treated carbons have been shown to catalyze various reactions including the elimination of halides from hydrocarbons [4], the decomposition of hydrogen peroxide and the oxidation of hydroquinone [16], and the oxidation of aqueous oxalic acid [1]. Boehm et al [6] have reported that the oxidation of dilute sulfurous acid or oxalic acid [3] is enhanced by carbons which have been heat-treated in ammonia at $600-900^{\circ} \mathrm{C}$. It has also been shown [4] by mass spectroscopic analysis of the reaction products that ammonia decomposes to $\mathrm{H}, \mathrm{NH}$ and $\mathrm{NH}_{2}$ radicals which react with carbon to produce methane, hydrogen cyanide and cyanogen as the main products. Routes to the formation of these products have been suggested [7].

$$
\begin{aligned}
\mathrm{H}+\mathrm{H} & \rightarrow \mathrm{H}_{2} \\
\mathrm{C}+2 \mathrm{H}_{2} & \rightarrow \mathrm{CH}_{4} \\
\mathrm{C} & +\mathrm{NH} \rightarrow \mathrm{HCN} \\
2 \mathrm{C}+2 \mathrm{NH}_{2} & \rightarrow(\mathrm{CN})_{2}+2 \mathrm{H}_{2}
\end{aligned}
$$

Although the above reactions are accompanied by carbon gasification at elevated temperatures, ammonia has not been previously applied to coal gasification. The choice of gas for coal gasification is determined primarily by the reactivities of the gases with carbon and the desire gasification products. Carbon dioxide, hydrogen, oxygen or steam, the frequently used gases for coal gasification, generate carbon monoxide, hydrogen, carbon 
dioxide or methane [17]. The potential feed stock base from coal gasification can be broadened by using ammonia to generate $\mathrm{HCN}$ or $(\mathrm{CN})_{2}$.

The current major process for the production of the latter gases involves the reaction of ammonia with methane and oxygen over costly platinum-rhodium catalysts at high temperature $[18,19]$. Hydrogen cyanide is used to manufacture a wide of reactive intermediates including adiponitrile, methyl methacrylate, cyanuric chloride and sodium cyanide used for the synthesis of fibers, plastics, herbicides, pharmaceuticals and surfactants $[18,19]$. The potential application of ammonia as a reactive medium for catalyzed coal gasification has been investigated and reported in this work.

\section{EXPERIMENTAL}

The demineralized derivative of North Dakota lignite (PSOC 1482, supplied by The Pennsylvania State University Coal Sample Bank ) was used for the study. The coal was supplied in sealed argon atmosphere to minimize oxidation. The original coal contained 5.6, 28.2, 31.8 and $34.5 \%$ wt. of ash, volatile matter, fixed carbon and moisture, respectively. The ultimate analysis (on dry ash-free basis) gave $0.8 \%$ wt. S, $1.1 \% \mathrm{wt} \mathrm{N}, 4.5 \% \mathrm{wt}$. $\mathrm{H}$ and $22.2 \%$ wt. $\mathrm{O}$ (by difference) as reported by the supplier. Demineralization was achieved by immersing the coal in $\mathrm{HF}$ and $\mathrm{HCl}$ solutions [20], with intermittent shaking, for several weeks after which it was filtered and thoroughly washed with deionized water.

Calcium or potassium ions were exchanged onto the coal by mechanically agitating (for $24 \mathrm{~h}$ ) $1.0 \mathrm{~g}$ of the demineralized coal in $50.0 \mathrm{~cm}^{3}$ of solution containing $5 \times 10^{-2} \mathrm{~mol} / \mathrm{L}$ of $\mathrm{Ca}^{2+}$ or $\mathrm{K}^{+}$using reagent grade calcium acetate or potassium carbonate as sources of the metals. The pHs of the coal dispersions were controlled with $\mathrm{HNO}_{3}$ and $\mathrm{NH}_{4} \mathrm{OH}$ solutions., using a few drops of $12.1 \mathrm{M} \mathrm{NH}_{4} \mathrm{OH}$ or $0.1 \mathrm{M} \mathrm{HNO}_{3}$ solutions. Metal-containing bases were not used to avoid introduction of metals which may have catalytic effects. The pHs of the slurries were measured prior to and after adsorption; the latter pHs are henceforth referred to 
as the equilibrium pHs. For the calcium loadings, the equilibrium pH values were 5.4 or 10.3 while the pHs for the potassium adsorption were 5.8 or 10.2. Calcium or potassium uptake was determined by chemical analysis (Galbraith Laboratories, Knoxville, TN) of the filtered coal particles.

A Dupont 951 thermogravimetric analyzer, interfaced with a microcomputer, was used to measure the weight changes during the gasification reactions. About $20 \mathrm{mg}$ samples of the unloaded and the calcium- or potassium-loaded coals were placed in a platinum pan and flushed with nitrogen at room temperature for $15 \mathrm{~min}$. The samples were then pyrolyzed by heating at a rate of $20^{\circ} \mathrm{C} \mathrm{min}-1$ from room temperature to $800^{\circ} \mathrm{C}$ in a continuous flow $(100$ $\mathrm{cm}^{3} \mathrm{~min}^{-1}$ ) of nitrogen and holding at this temperature for $30 \mathrm{~min}$. Char reactivity was initiated by replacing the $\mathrm{N}_{2}$ supply with a $100 \mathrm{~cm}^{3} \mathrm{~min}^{-1}$ flow of anhydrous grade ammonia, (99.99\% minimum purity). Carbon burn-off was allowed to proceed for about $1 \mathrm{~h}$.

\section{RESULTS AND DISCUSSION}

Comparison of Figures 1 and 2 shows that the calcium- or potassium-containing chars are more reactive than the unloaded char. In general, a small increase in the catalyst content of the chars caused an apprecible increase in reactivity, as indicated by the reactivities for 2.5 and $2.6 \%$ wt. Ca or .5 and $.6 \%$ wt potassium loadings in Figures 1 and 2 respectively. However, the gasification rates are similar for the calcium or potassium catalysts, except for the calcium-loaded samples which show similar burn-ori above $\sim 50 \mathrm{~min}$. of reaction. These findings are in contrast to those we obtained in previous work for carbon dioxide gasification of chars containing similar calcium or potassium contents [21]. The same demineralized

lignite and $\mathrm{Ca}$ or $\mathrm{K}$ precursors were used in both studies. In the previous work, char reactivity was more enhanced, at equivalent loadings, for potassium than calcium. Similar higher activities have been reported for potassium [21]. 
In synopsis, for the first time, the application of ammonia as a reactive medium for catalyzed coal gasification has been investigated. The results show that the addition of calcium or potassium to samples of a demineralized lignite significantly enhanced char gasification compared to the sample without added catalysts and indicate that ammonia can be an effective medium for coal gasification.

\section{REFERENCES}

1. E. K. Rideal and W. M. Wright, J. Chem. Soc. (London), (1926) 1813.

2. B. Tereczki, R. Kurth and H. P. Boehm, Prepr. Carbon '80, Int. Carbon Conf. BadenBaden, FRG (1980) p. 218.

3. R. Kurth, B. Tereczki and H. P. Boehm, 15th Biennial Conf. on Carbon, Philadelphia, PA, Ext. Abstr. (1981) p. 244.

4. H. P. Boehm, G. Mair, T. Stohr, A.R. de Rincon and B. Tereczki, Fuel, 63 (1984) 1061.

5. H. P. Boehm, A. R. de Rincon, T. Stohr, B. Tereczki and A. Vass, J. Phys.-Chim. Biol., Paris 84 (1987) 1449.

6. B. Stohr, H. P. Boehm and R. Schlogl, Carbon, 29 (1991) 707.

7. G. M. K. Abotsi and A.W. Scaroni, Carbon, 28 (1990) 79.

8. G, M. K. Abotsi, A. W. Scaroni and F. J. Derbyshire, Appl. catal., 37 (1988) 93.

9. F. J. Derbyshire, V. H. J. de Beer, G. M. K. Abotsi, A. W. Scaroni, J. M. Solar and D. J. Skrovanek, Appl. Catal. 27 (1986) 117.

10. B. R. Puri and O. P. Mahajan, J. Indian Chemi Soc., 41 (1964) 586.

11. M. L. Studebaker, Rubber Age, 80 (1957) 661.

12. M. L. Studebaker, Rubber Chem. Tech. 30 (1957) 1400.

13. R. B. Anderson and P. H. Emmett, J. Phys. Chem., 56 (1952) 753.

14. P. H. Emmett, Chem. Rev., 43 (1948) 69. 
15. C. J. J. Baraniecki and H. L. Riley, Proc. 3rd Conf. Carbon, Buffalo, NY, 1959, p. 69.

16. P. F. Bente and J. H. Walton, J. Phys. Chem., 47 (1943) 133, 329.

17. J. L. Johnson, In Fundamentals of Coal Utilization, 2nd Supplementary Volume, M.A. Elliot, Ed., John Wiley, New York, 1981, p. 1491.

18. Riegel's Handbook of Industrial Chemistry, 8th Edn., J. A. Kent, Ed., Van Nostrand Reinhold, New York, 1983, p. 198.

19. Kirk-Othmer Ecyclopedia of Chemical Technology, Vol. 7, John Wiley \& Sons, New York, 1979, p. 307.

20. L. R. Radovic, r. G. Jenkins and P. L. Walker, Jr., Fuel 58 (1979) 338.

21. G. M. K. Abotsi, K. B. Bota and G. Saha, "Effects of Coal Surface Charge on the Adsorption and Gasification Activities of Calcium and Potassium," Fuel Sci. Tech. Int., in press. 


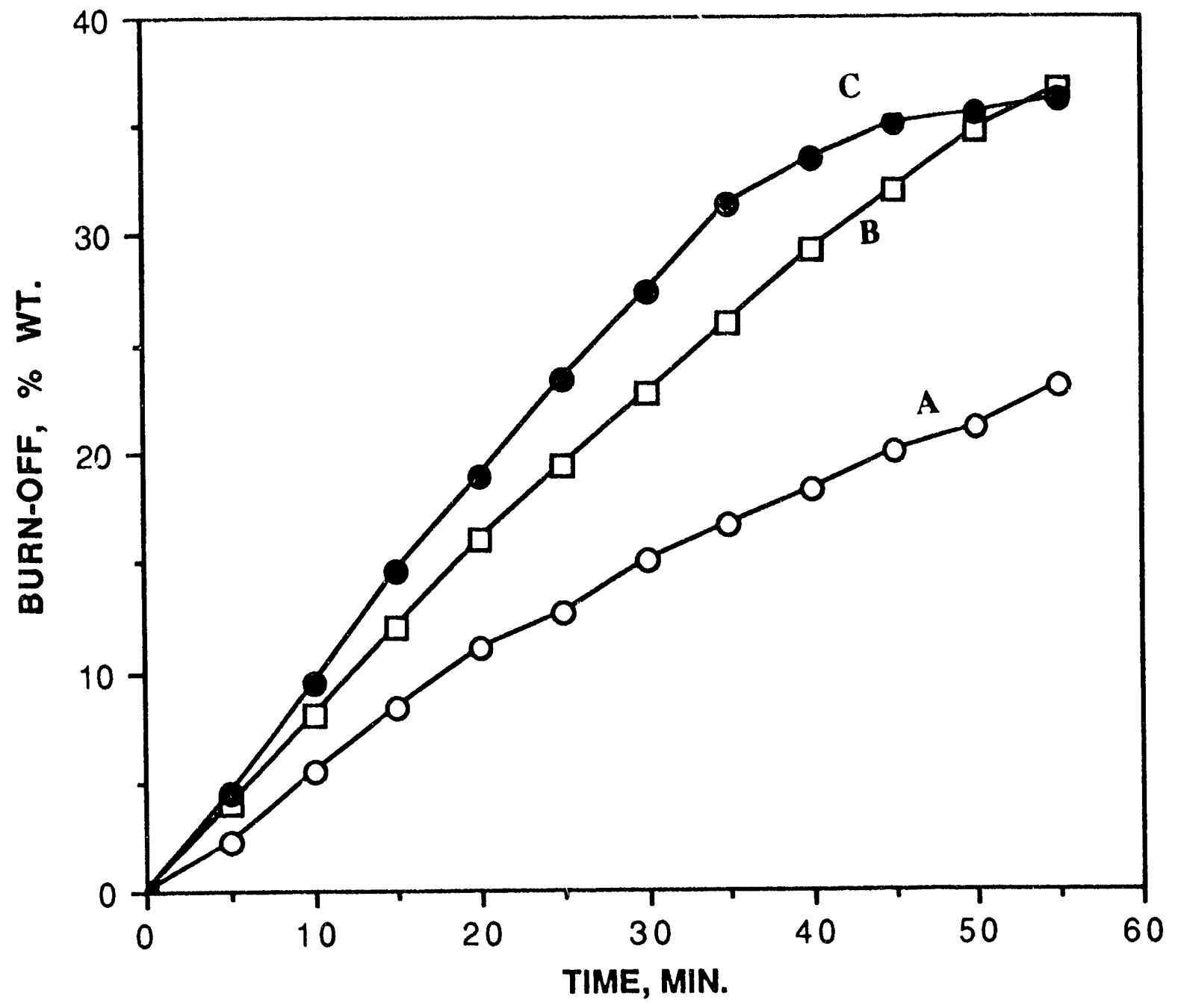

Figure 1. Reactivities of the unloaded char (A), and the char containing 2.5 (B) and $2.6 \%$ wt. calcium (C). 


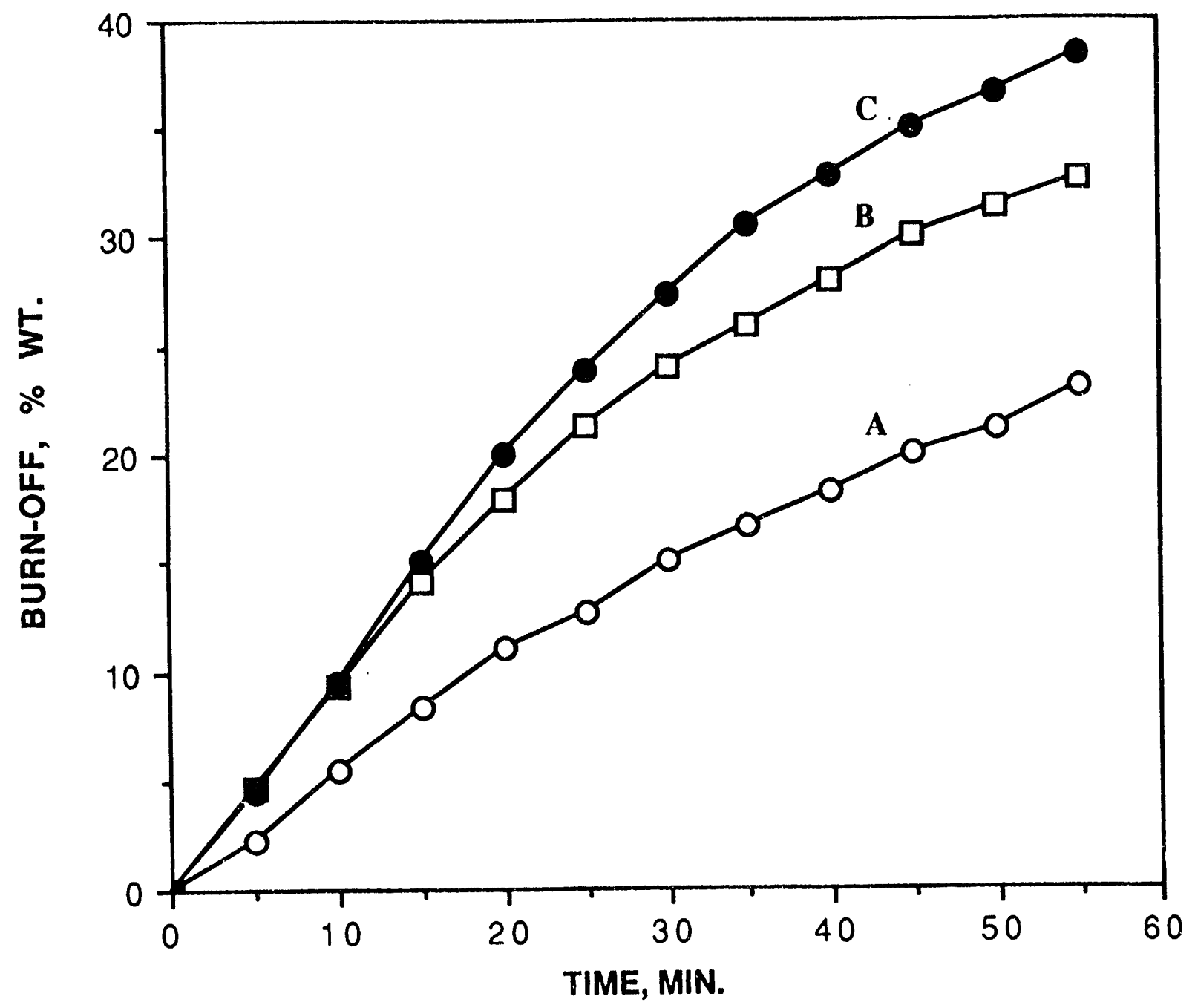

Figure 2. Reactivities of the unloaded lignite char (A), and the char containing 0.5 (B) and $0.6 \%$ wt. potassium (C). 

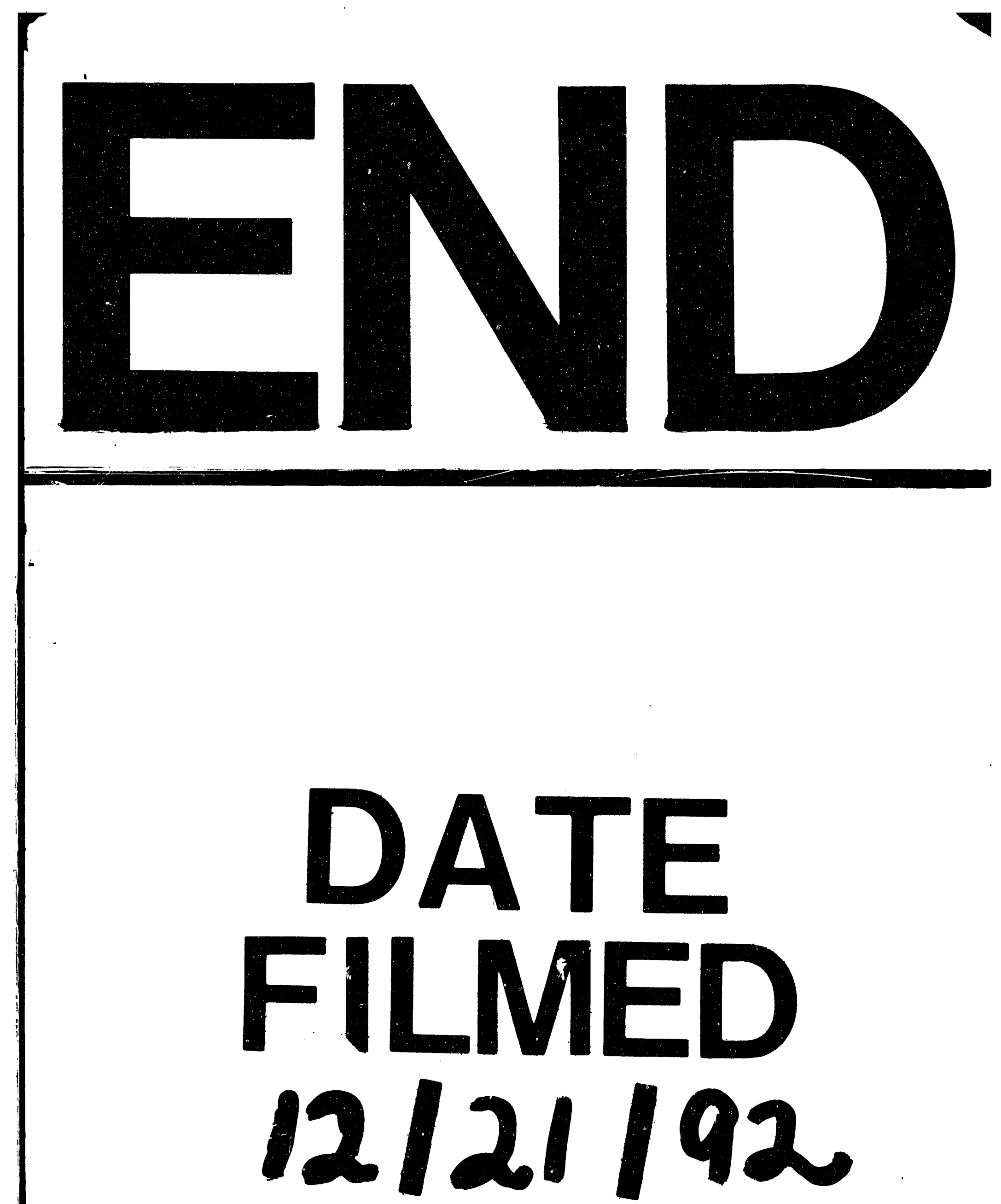
